\title{
Oxidative stress among informal caregivers
}

Natália Ramos Imamura de Vasconcelos' Gilsenir Maria Prevelato de Almeida Dátilo ${ }^{2}$ (D) Agnaldo Bruno Chies 3 (D) Eduardo Federighi Baisi Chagas ${ }^{4}$ (D) Thiago José Querino de Vasconcelos ${ }^{5}$ (D) Pedro Marco Karan Barbosa ${ }^{6}$ (D)

\section{Abstract}

Objective: to evaluate oxidative stress and non-enzymatic antioxidant defenses in informal caregivers, and correlations with anxiety, health satisfaction and quality of life. Method: a case-control analytical study was performed, where the case was represented by the main informal caregiver and the control was paired with individuals with identical characteristics to the case, but who were not informal caregivers. The following instruments were used: a sociodemographic questionnaire, the Beck anxiety scale and the WHOQoL-Bref. Oxidative stress was measured through blood by analysis of the Ferric Reducing Ability of Plasma (FRAP) and Thiobarbituric Acid Reactive Substances (TBARS) markets. Results: most informal caregivers were females. There was no difference in the degree of anxiety between the Case and Control groups. Among informal caregivers, 9.4\% said they were very dissatisfied and $53.1 \%$ dissatisfied with their health. Most caregivers (43.8\%) rated their quality of life as poor and $12.5 \%$ as very poor, while most controls rated it as good $(68.8 \%)$. The TBARS and FRAP values were lower in the Case group than in the Control group. Conclusion: The informal caregivers, who were mostly women, defined themselves as dissatisfied or very dissatisfied with their health. Nevertheless, they did

Faculdade de Medicina de Marília (FAMEMA), Pós-graduação em Saúde e Envelhecimento. Marília, SP, Brasil.

2 Universidade Estadual Paulista Júlio Mesquita Filho (UNESP), Departamento de Psicologia da Educação. Marília, SP, Brasil.

3 Faculdade de Medicina de Marília (FAMEMA), Departamento de Farmacologia, Pós-graduação em Saúde e Envelhecimento. Marília, SP, Brasil.

4 Universidade de Marília, Departamento de Educação Fïsica. Faculdade de Medicina de Marília, Programa de Pós-graduação em Saúde e Envelhecimento. Marília, SP, Brasil.

5 Hospital Beneficente da Universidade de Marília (UNIMAR), Departamento de Anestesiologia. Marília, SP, Brasil.

6 Faculdade de Medicina de Marília (FAMEMA), Departamento de Enfermagem clínica, Pós-graduação em Saúde e Envelhecimento. Marília, SP, Brasil.

Funding: Programa Demanda Social Coordenação de Aperfeiçoamento Pessoal de Nível Superior (CAPES). Number of process: 1758470.

The authors declare there are no conflicts of interest in relation to the present study.

Correspondência

Natália Ramos Imamura de Vasconcelos

natalia@saudecordis.com.br
Keywords: Caregivers

Oxidative Stress. Quality of

Life. Anxiety.
Received: March 15, 2019 Approved: September 17, 2019 
not manifest a higher degree of anxiety in comparison with the control population. In addition, they presented a lower degree of oxidative stress than the non-caregiving participants, perhaps due to a greater mobilization of the non-enzymatic antioxidant defenses present in the body.

\section{INTRODUCTION}

Free radicals are continuously formed in the human body as a result of aerobic metabolism or by the action of enzymatic systems such as NAD $(\mathrm{P})$ $\mathrm{H}$ oxidases, catalases and nitric oxide synthases. In small concentrations these substances, play important physiological roles in intracellular and intercellular signaling and hormone production.

However, when the production of free radicals exceeds the capacity of antioxidant systems, a pathophysiological condition called oxidative stress occurs. So that free radical concentrations do not become elevated, the human body possesses enzymatic and non-enzymatic antioxidant systems capable of eliminating them ${ }^{1-4}$. These mechanisms are important since excess free radicals react with proteins, lipids, carbohydrates and DNA, leading to many diseases prevalent in aging ${ }^{5}$. The products generated by the reaction of free radicals with these cellular constituents, including lipoperoxides, are considered important biomarkers of oxidative stress $^{6}$. The redox balance can also be estimated by determining the ability of the plasma to reduce ferric ion, which reflects the action of the non-enzymatic antioxidant defenses present in this biological fluid?

Oxidative stress can be aggravated by exposure to environmental agents such as pollution and cigarette smoke which contain free radicals, or by the consumption of alcohol and drugs that increase the endogenous production of these substances ${ }^{8,9}$. Sedentary individuals are more likely to have higher levels of oxidative stress, as they do not properly develop their antioxidant defenses ${ }^{4}$. Oxidative stress is also higher in individuals subjected to mental stress and psychiatric illness, although the causal relationship between these pathophysiological conditions is still poorly known'. Thus, the mitigation of oxidative stress involves a balanced diet, physical activity, reduced alcohol and tobacco consumption, reduced mental stress, and improved environmental conditions.
Informal caregivers, as they dedicate themselves exclusively to others, can experience significant changes in their lifestyle and habits. Thus, they may neglect their diet or daily practice of physical activity and, therefore, may present a higher degree of oxidative stress. Informal caregivers may also have a higher degree of mental stress and anxiety. In fact, it is estimated that around $90 \%$ of the world's population may be affected by mental stress, which may be considered the most worrying factor of the modern age ${ }^{10}$.

Situations that threaten the physical and emotional security of the individual, in the short and long term, involving their reputation and self-esteem, are among the factors that most trigger stress situation ${ }^{11}$. In this sense, some scales are useful, such as the Beck anxiety scale $^{12}$ and the WHO (World Health Organization) quality of life scale ${ }^{13}$ to investigate stress in day to day life ${ }^{14}$.

With population aging, there is a tendency for the number of older adults to depend partially or totally on care. It is increasingly common for someone to take on the role of informal caregiver of such older people, usually a family member. This leads to changes or redefinitions of the roles of one or more family members. These caregivers assume the responsibility of caring, most often without technical preparation, for up to 24 hours a day. Thus, the caregiver "gives up most of their daily life, mainly abdicating leisure and paid work, which significantly changes their life dynamics and the dynamics of family life" 14 .

The act of caring represents a challenge to the caregiver, as it causes physical and emotional exhaustion and overload, as well as financial costs, added to the risks of mental and physical illness. Caring is an act of bondage because the caregiver offers the best of his or her talents to others ${ }^{15}$. -Caregivers commonly manifest extreme tiredness; general fatigue; pains; physical and emotional exhaustion and overload; loss of resistance; nervousness; 
irritability; anxiety; insomnia; depression, among other symptoms. This indicates that, in most cases, caring for others implies neglecting oneself, which directly impacts the caregiver's quality of life $\mathrm{e}^{16,17}$.

The informal caregiver is one who cares voluntarily, usually represented by a family member, and may also be a friend or neighbor ${ }^{18}$. In Brazil, it is more common for the family to assume the role of caring ${ }^{19}$. Caring for an older family member is a subjective experience. Daily care becomes a challenge where, suddenly and often without knowledge and/ or support, this family member now takes on a new role, becoming a caregiver ${ }^{20}$.

In this context, a new sphere to be encompassed by health services has emerged: home care. This is because families increasingly need to play the role of caregivers, both in order to maintain a sick family member or older adult in the family environment and to better manage resources that are often limited and prevent the hiring of a professional care provider ${ }^{21}$.

In this sense, the aim of the present study was to evaluate oxidative stress and non-enzymatic antioxidant defenses in informal caregivers, comparing the data obtained with non-caregivers, and correlating the results with degree of anxiety, health satisfaction and quality of life.

\section{METHOD}

A case-control analytical study was performed, where the cases were represented by primary informal caregivers, matched with individuals with identical gender and age characteristics who were not informal caregivers as controls.

The study was conducted in partnership with the Interdisciplinary Home Hospitalization Program (or PROIID) of the city of Marília, in the state of São Paulo, Brazil. This program accompanies patients and family members who, although they no longer need intensive in-hospital care, require care and guidance to improve their health-disease process, as well as restore their physical, emotional and mental integrity. The program is a partnership between the Clinical Hospital and the Municipal Health Department.
Informal caregivers who performed this role fully for six months or more, referred to as "cases", were included in the study. These caregivers were selected through direct contact between the principal researcher and the relevant PROIID nurse. In this contact, the users of the program who were dependent on care were identified, with the subsequent need for an informal caregiver for a minimum of 12 hours per day, referred to in literature as a primary caregiver. These were selected after consulting the PROIID database. For the control, pairs with the same characteristics, such as age and gender, but who did not currently perform the role of caregiver, or who had not performed it for at least one year, were selected. The cases and the controls were matched one to one. All subjects involved in the study were over 18 years of age.

Individuals who agreed to participate were initially asked if they had been diagnosed with systemic arterial hypertension, diabetes mellitus, and dyslipidemia, as well as whether they were smokers or alcoholics. Active smokers and alcoholics were excluded from both groups due to the recognized influence of these factors on the oxidative stress assessment parameters used. Survey participants were advised not to consume processed foods and not to drink alcohol for three days prior to blood collection.

The data was collected from July to November 2018, exclusively by the principal researcher. The Beck anxiety scale ${ }^{12}$ and the World Health Organization Quality of Life Questionnaire (WHOQOL-bref) were applied ${ }^{13}$.

The Beck's anxiety scale consists of 21 multiple choice questions and measures the individual's degree of anxiety, which may be mild, moderate or severe. It provides a score ranging from 0 to 63 , with the degree of anxiety is proportional to the score ${ }^{12}$. The WHOQOL-bref, meanwhile, is a WHO-validated instrument to measure quality of life, divided into domains, namely: physical, psychological, social relations and environment ${ }^{22}$. Both instruments were applied individually.

Next, blood samples were collected from the participants to obtain plasma. These collections were made in the morning, between 8 am and 10 am. Blood samples were collected in an EDTA tube and refrigerated at the Pharmacology Laboratory of 
the Marilia Medical School (Famema) within one hour. In the laboratory, the samples were centrifuged for 10 minutes at $4^{\circ} \mathrm{C}$, with rotation of $3000 \mathrm{rpm}$ in a Hermle centrifuge. After centrifugation, the plasma was collected by pipette and transferred to another tube, where it was stored at $-80^{\circ} \mathrm{C}$ for further analysis of plasma lipoperoxide concentration by the Thiobarbituric Acid Reactive Substances (TBARS) ${ }^{6}$ technique. These samples were also used to determine the ability of plasma to reduce ferric ion by the FerricReducing Ability of Plasma (FRAP) technique?.

Sample size calculation was performed using the G*Power software program, version 3.1.9.2 (Franz Faul, Universität Kiel, Germany) to analyze oxidative stress in a case-control study using the Student t-test for independent samples.

Data normality distribution was verified by the Kolmogorov-Smirnov test. For comparison between two independent groups, the Student's t-test for unpaired samples or the nonparametric Mann-Whitney test were performed. To analyze the frequency distribution between the categories of qualitative variables, the Chi-square test for proportion was used. To analyze the relationship between two qualitative variables, the Chi-square test for proportion was applied. For all analyzes the SPSS software version 19.0 for windows was used, adopting a significance level of $5 \%$.

The study was submitted to the Famema Research Ethics Committee, and was approved on December 14, 2017, under Opinion No. 2,439,044. Participants signed a Free and Informed Consent Form (FICF) to participate in this study, in compliance with National Health Council Resolution No. 466/2012.

\section{RESULTS}

There was no initial significant difference between the case and control groups regarding the distribution of the variables gender, diabetes mellitus, dyslipidemia, systemic arterial hypertension, age group and sedentary lifestyle (Table 1).

Table 1. Absolute (n) and relative (\%) frequency distribution of sample characteristics between case and control groups. Marília, São Paulo, 2018.

\begin{tabular}{|c|c|c|c|}
\hline \multirow{3}{*}{ Variables } & \multicolumn{2}{|c|}{ Groups } & \multirow{3}{*}{$p$} \\
\hline & Case $(\mathrm{n}=32)$ & Control $(n=32)$ & \\
\hline & n $(\%)$ & $\mathrm{n}(\%)$ & \\
\hline \multicolumn{4}{|l|}{ Sex } \\
\hline Female & $28(87.5)$ & $28(87.5)$ & \multirow[t]{2}{*}{0.646} \\
\hline Male & $4(12.5)$ & $4(12.5)$ & \\
\hline \multicolumn{4}{|c|}{ Diabetes mellitus } \\
\hline Present & $7(21.9)$ & $4(12.5)$ & \multirow[t]{2}{*}{0.324} \\
\hline Absent & $25(78.1)$ & $28(87.5)$ & \\
\hline \multicolumn{4}{|c|}{ Dyslipidemia } \\
\hline Present & $5(15.6)$ & $8(25.0)$ & \multirow[t]{2}{*}{0.355} \\
\hline Absent & $27(84.4)$ & $24(75.0)$ & \\
\hline \multicolumn{4}{|c|}{ Arterial hypertension } \\
\hline Present & $12(37.5)$ & $10(31.3)$ & \multirow[t]{2}{*}{0.602} \\
\hline Absent & $20(62.5)$ & $22(68.8)$ & \\
\hline \multicolumn{4}{|c|}{ Age range (years) } \\
\hline$<60$ & $20(62.5)$ & $22(68.8)$ & \multirow[t]{2}{*}{0.602} \\
\hline$\geq 60$ & $12(37.5)$ & $10(31.3)$ & \\
\hline \multicolumn{4}{|c|}{ Sedentary lifestyle } \\
\hline Yes & $27(84.4)$ & $24(75.0)$ & \multirow[t]{2}{*}{0.355} \\
\hline No & $5(15.6)$ & $8(25.0)$ & \\
\hline
\end{tabular}

$p$ calculated by the chi-square association test. 
The group of caregivers was made up of family members, predominantly female, especially daughters and wives (Table 2). For each participant in the case group, there was a same-sex participant, not belonging to the same family, in the control group.

The data obtained also show that there was no statistical difference in the degree of anxiety between individuals who performed the informal caregiver role and those who did not. Most individuals in the case group had minimal anxiety in comparison with control. Regarding satisfaction with health, no individual in the control group expressed dissatisfaction, while $9.4 \%$ of informal caregivers expressed such an opinion by answering the specific health-related question in the WHOQOL-bref. The alarming fact about this issue is that most caregivers, i.e. 17 (53.1\%) participants, were dissatisfied with their health. Most caregivers $(43.8 \%)$ rated their quality of life as poor, while most controls $(68.8 \%)$ rated it as good (Table 3$)$.

Table 2. Absolute (n) and relative (\%) frequency distribution of caregiver kinship in case group. Marília, São Paulo, 2018.

\begin{tabular}{lll}
\hline Kinship & $\mathrm{n}(\%)$ & p-value \\
\hline Wife & $8(25.0)$ & \\
Daughter & $19(59.4)$ & $0.0001^{*}$ \\
Sister & $1(3.1)$ & \\
Husband & $4(12.5)$ & \\
Total & $32(100.0)$ & \\
\hline
\end{tabular}

* Significant difference $(\mathrm{p} \leq 0,0001)$ in the distribution of kinship proportion in the caregiver sample by the chi-square association test.

Table 3. Analysis of the association of cases and controls in the qualitative variables degree of anxiety, health satisfaction and quality of life. Marilia, São Paulo, 2018.

\begin{tabular}{|c|c|c|c|}
\hline \multirow[b]{2}{*}{ Variables } & \multicolumn{2}{|c|}{ Groups } & \multirow[t]{2}{*}{$p$} \\
\hline & $\begin{array}{l}\text { Case } \\
\mathrm{n}(\%)\end{array}$ & $\begin{array}{l}\text { Control } \\
\mathrm{n}(\%)\end{array}$ & \\
\hline \multicolumn{4}{|c|}{ Anxiety Degree (Beck Scale) } \\
\hline Minimum & $18(56.3)$ & $15(46.9)$ & \multirow{4}{*}{0.170} \\
\hline Mild & $5(15.6)$ & $12(37.5)$ & \\
\hline Moderate & $8(25.0)$ & $4(12.5)$ & \\
\hline Severe & $1(3.1)$ & $1(3.1)$ & \\
\hline \multicolumn{4}{|c|}{ Health satisfaction (questionnaire WHOQOL-bref) } \\
\hline Very unsatisfied & $3(9.4)$ & $0(0.0)$ & \multirow{5}{*}{$0.003^{*}$} \\
\hline Dissatisfied & $17(53.1)$ & $7(21.9)$ & \\
\hline Dissatisfied/Satisfied & $8(25.0)$ & $9(28.1)$ & \\
\hline Pleased & $4(12.5)$ & $12(37.5)$ & \\
\hline Very satisfied & $0(0.0)$ & $4(12.5)$ & \\
\hline \multicolumn{4}{|c|}{ Quality of life (questionnaire WHOQOL-bref) } \\
\hline Very poor & $4(12.5)$ & $1(3.1)$ & \multirow{5}{*}{$0.0001^{*}$} \\
\hline Poor & $14(43.8)$ & $3(9.4)$ & \\
\hline Poor/Good & $7(21.9)$ & $2(6.3)$ & \\
\hline Good & $7(21.9)$ & $22(68.8)$ & \\
\hline Excellent & $0(0.0)$ & $4(12.5)$ & \\
\hline
\end{tabular}

* Significant difference ( $\mathrm{p}$-value $\leq 0.05$ ) by Chi-square test. 
The data obtained also showed differences between the groups in relation to TBARS values. Participants in the case group were found to have lower TBARS values compared to those in the control group. In contrast, FRAP values were lower in the case group than in the control group (Table 4).

Table 4. FRAP and TBARS values obtained in control and case groups. Marília, São Paulo, 2018.

\begin{tabular}{llll}
\hline \multirow{2}{*}{ Variables } & \multicolumn{1}{c}{ Groups } & & $p$-value \\
& $\begin{array}{l}\text { Case }(\mathrm{n}=32) \\
\text { Mean (standard-deviation) }\end{array}$ & Control $(\mathrm{n}=32)$ & \\
\hline TBARS $(\mathrm{mg} / \mathrm{mol})$ & $18.70( \pm 19.56)$ & $41.98( \pm 27.31)$ & $0.0001^{* *}$ \\
\hline FRAP $(\mathrm{mg} / \mathrm{mol})$ & $1.09( \pm 0.23)$ & $1.36( \pm 0.20)$ & $0.0001^{*}$ \\
\hline
\end{tabular}

* Significant difference $(\mathrm{p} \leq 0.0001)$ between groups by Student's t-test for independent samples; $* *$ significant difference $(\mathrm{p} \leq 0.0001)$ between groups by the nonparametric Mann-Whitney test.

\section{DISCUSSION}

In the present study, it was observed that due to performing the role of informal caregiver, the population included in the case group was predominantly composed of women, all of whom are family members of the care recipient ${ }^{23,24}$. These data are in line with literature that indicates that women predominantly assume the role of caregiver throughout the world, reflecting a culture rooted in the idea that caring is part of the female reality ${ }^{25}$. It should be considered that the caregiver is the main target of family tension caused by the stress and tiredness involved in care. Thus, due to the global increase in life expectancy, families must be socially and economically prepared to understand and support the role of the informal caregiver ${ }^{26}$. These caregivers, predominantly women, are also responsible for the link between the health team and the patient ${ }^{27}$, and are thus an essential figure for the success of home care.

During data collection, it was common for the participant caregivers to report disturbed sleep patterns, as they often needed to wake up several times during the night to check the condition of the individual under their care (unquantified data). These caregivers complained that this compromised their daily activities. Another problem is a sedentary lifestyle, which was frequently found among the participants in both the case and control groups. In addition, there was a frequent complaint among informal caregivers about a lack of leisure opportunities, as they had no one to leave the care- dependent family member with during the time spent on this purpose.

Another highly relevant factor, related to the link between women and the work of informal caregivers, is the misunderstanding, on the part of society in general, that caring is female in nature. In fact, care-related work represents an imposition on women. This understanding stems from the historic organization of the family in Brazil and in other countries, in which women were given all the domestic responsibilities, including looking after the recipient of care. According to Guedes ${ }^{24}$, during their productive lives, women are more likely to give up their careers, including because of maternity care. Thus, this removal from the labor market is prolonged through the continuation of the role of caregiver for a family member. In addition, the labor laws in force in Brazil, with inflexible hours that do not consider double shifts, make it difficult to reinsert these caregivers in the labor market after the period dedicated to care, leading them unemployed.

Several instruments aimed at assessing quality of life have been described and validated in literature, of which the WHOQOL-bref, used in the present study, is one of the most important. In the data collected by this instrument lower scores were identified in the psychological and interpersonal relationships domains, which are indicated in literature as being some of the main burdens of performing the role of informal caregiver. Caring results in physical, psychological and social burden. This is not only due to caregiving, which is important in itself, but is aggravated by the 
fact that the caregivers, mostly women, accumulate extra duties related to household chores. This further increases the physical and social burden of the informal caregiver ${ }^{28}$.

It is noteworthy that about $10 \%$ of caregivers surveyed said they were very dissatisfied with their health and more than half said they were dissatisfied. These data are reinforced by a previous study in which a direct relationship was detected between negative self-rated health and increased burden imposed by the act of caring, as well as reduced happiness perceived by the caregiver ${ }^{29}$. Other authors have also observed an association between self-rated health and well-being ${ }^{26,30}$. According to these authors, health is a multidimensional factor and psychological well-being can influence it. This proposition is based on the WHO concept that health does not only involve the absence of disease, but is the result of the sum of physical, psychological and social well-being. In addition, in this study, health-related quality of life was a predictive factor for increased psychological well-being.

Regarding the self-assessment of overall quality of life, it is noteworthy that $43.8 \%$ of caregivers rated their quality of life as poor and $12.5 \%$ said it was very poor. Factors related to burden in care work and health conditions are those that most significantly affect the self-assessment of quality of life of caregivers.

When assessing the TBARS of informal caregivers, a somewhat unexpected panorama was observed. This is because, despite declaring themselves dissatisfied with their health and classifying their quality of life as poor, informal caregivers had lower TBARS values than those observed in the control group. As already mentioned, TBARS is a parameter that indicates the degree of oxidative stress, as it quantifies the lipoperoxidation end products ${ }^{6}$. Thus, it can be said that despite the life and health conditions to which informal caregivers are subjected, they present a lower degree of oxidative stress. In this sense, it should be emphasized that chronic oxidative stress may be the genesis of several highly prevalent and often severe chronic degenerative diseases ${ }^{2,8}$. Indeed, these data are somewhat reassuring, as they suggest that the risk of illness in these caregivers surveyed is not elevated by oxidative stress.
These data, however, reveal the complexity of oxidative balance in humans and the challenge of studying it in such a dynamic condition as the daily life of an informal caregiver. If on the one hand informal caregivers are dissatisfied with their health and realize that their quality of life is inadequate, on the other hand they may be less exposed to several factors that are highly pro-oxidative. To illustrate this reality, it is worth noting that informal caregivers also did not exhibit a higher degree of anxiety than the control group. This is not to say that the living conditions of an informal caregiver are unhealthy, but does warn of the possible existence of other factors that can mitigate oxidative stress in these individuals. Identifying these factors and how they relate to oxidative balance is a challenge that emerged from the present study.

In this sense, it is worth noting that the difference in the degree of stress observed between the case and control groups is unlikely to be related to the prevalence of diabetes mellitus, dyslipidemia and systemic arterial hypertension in the groups. This is because, although these diseases are closely related to oxidative stress ${ }^{31,32}$, there were no differences in the prevalence of the same between the case and control groups. There were also no differences between the groups regarding age and physical inactivity, factors that are also known to aggravate oxidative stress ${ }^{2,31}$.

As mentioned, oxidative stress is a result of the imbalance between oxidant production and antioxidant defenses. This imbalance can result, on the one hand, from the excessive production of free radicals and/or the high uptake of free radicals from the environment, and, on the other, from a lower ability to eradicate the same by the antioxidant defenses present in the body ${ }^{2}$. Thus, when assessing oxidative stress, special attention should be paid to the body's antioxidant defenses. In this sense, the present study also evaluated the capacity of the non-enzymatic antioxidant defenses present in the plasma of the individuals studied, using the FRAP technique. In fact, the antioxidant capacity measured by FRAP reflects the sum of the antioxidant actions of various components of biological fluids, including uric acid and ascorbic acid, which exert approximately $60 \%$ and $20 \%$ of the evaluated antioxidant capacity, respectively. FRAP also influences the presence 
of vitamin E, bilirubin and albumin? 7 Given these considerations, the importance of a balanced diet for the proper functioning of these antioxidant defenses present in plasma is evident. It is interesting to note that the informal caregivers had reduced FRAP values, in comparison with the control group. This indicates that, in these individuals, the reduction of oxidative stress, characterized by the reduction in TBARS values, may have occurred due to the higher consumption of non-enzymatic antioxidant defenses, as measured by FRAP. However, why this mobilization of antioxidant defenses is greater in informal caregivers, to the point of perhaps reducing the degree of oxidative stress in these individuals, remains unknown.

\section{CONCLUSION}

Based on the data of the present study, it can be concluded that the informal caregivers were predominantly women from the family circle of the individual under care. This is explained by a culture that is rooted in the idea that caring is part of the female reality. These caregivers mostly define themselves as dissatisfied or very dissatisfied with their health, and more than half of them rate their quality of life as poor or very poor. Nevertheless, these caregivers did not show a higher degree of anxiety in relation to the population that did not perform care-related tasks.

Finally, the informal caregivers exhibited a lower degree of oxidative stress than the non-caregivers, perhaps due to the greater mobilization of nonenzymatic antioxidant defenses present in the body. These data suggest that the risk of illness among these caregivers due to oxidative stress does not appear to be high. This is not to say that the living conditions of informal caregivers are unhealthy, but does warn of the possible existence of other factors that may mitigate oxidative stress in these individuals.

Edited by: Ana Carolina Lima Cavaletti

\section{REFERENCES}

1. Halliwell B. The antioxidant paradox. Lancet. 2000;355(9210):1179-80.

2. Engers VK, Behling CS, Frizzo MN. A influência do estresse oxidativo no processo de envelhecimento. Rev Contexto Saúde. 2011;11(20):93-102.

3. Sies H. Oxidative stress: a concept in redox biology and medicine. Redox Biol. 2015;4:180-3.

4. Poblete-Aro C, Russell-Guzmán J, Parra P, SotoMuñoz M, Villegas-González B, Cofré-Bolados C, et al. Exercise and oxidative stress in type 2 diabetes mellitus. Rev Med Chil. 2018;146(3):362-72.

5. Barreiros ALBS, David JM, David JP. Estresse oxidativo: relação entre geração de espécies reativas e defesa do organismo. Quím Nova. 2006;29(1):113-23.

6. Wills E. Mechanism of lipid peroxide formation in animal tissues. Biochem J. 1966;99(3):667-76.

7. Benzie IFF, Strain JJ. The Ferric Reducing Ability of Plasma (FRAP) as a measure of "Antioxidant Power": the frap assay. Anal Biochem. 1996;239(11):70-6.

8. Aseervatham GS, Sivasudha T, Jeyadevi R, Arul Ananth D. Environmental factors and unhealthy lifestyle influence oxidative stress in humans: an overview. Environ Sci Pollut Res Int. 2013;20(7):4356-69.

9. Golbidi S, Li H, Laher I. Oxidative stress: a unifying mechanism for cell damage induced by noise, (WaterPipe) smoking, and emotional stress-therapeutic strategies targeting redox imbalance. Antioxid Redox Signal. 2018;28(9):741-59.

10. Anjos KF, Boery RNSO, Pereira R. Qualidade de vida de cuidadores de idosos dependentes no domicílio. Texto Contexto Enferm. 2014;23(3):600-8.

11. Barcaui A, Limongi-França AC. Estresse, enfrentamento e qualidade de vida: um estudo sobre gerentes brasileiros. Rev Adm Contemp. 2014;18(5):670-94.

12. Leyfer OT, Ruberg JL, Woodruff-Borden J. Examination of the utility of the Beck Anxiety Inventory and its factors as a screener for anxiety disorders. J Anxiety Disord. 2006;20(4):444-58.

13. The World Health Organization Quality of Life Assessment (WHOQOL): position paper from the health organization. Soc Sci Med. 1995;41(10):1403-9.

14. Prudente COM, Ribeiro MFM, Porto CC. Qualidade de vida de cuidadores familiares de adultos com lesão medular: uma revisão sistemática. Ciênc Saúde Colet. 2017;22(1):123-34 
15. Queiroz RS, Camacho ACLF, Gurgel JL, Assis CRC, Santos LM, Santos MLSC. Perfil sociodemográfico e qualidade de vida de cuidadores de idosos com demência. Rev Bras Geriatr Gerontol. 2018;21(2):210-9.

16. Flesch LD, Batistoni SST, Neri AL, Cachioni M. Psychological aspects of the quality of life of caregivers of the elderly: an integrative review. Geriatr Gerontol Aging. 2017;11(3):138-49.

17. Ornstein K, Gaugler JE, Zahodne L, Stern Y. The heterogeneous course of depressive symptoms for the dementia caregiver. Int J Aging Hum Dev. 2014;78(2):133-48.

18. Buyck JF, Ankri J, Dugravot A, Bonnaud S, Nabi H, Kivimäki M, et al. Informal caregiving and the risk for coronary heart disease: the Whitehall II Study. J Gerontol Ser A Biol Sci Med Sci. 2013;68(10):1316-23.

19. Perkins M, Howard VJ, Wadley VG, Crowe M, Safford MM, Haley WE, et al. Caregiving strain and all-cause mortality: evidence from the Regards Study. J Gerontol Ser B Psychol Sci Soc Sci. 2013;68(4):504-12.

20. Dátilo GMPA, Horiguela MLM. Idosos dependentes: o lugar do familiar cuidador. In: Bruns MAT, Del-Masso MCS, organizadoras. Envelhecimento humano: diferentes perspectivas. Campinas: Alínea; 2007. p. 143-66.

21. Góis DCB. Vivências subjetivas na arte de cuidar idosos no seio familiar: o impacto psicossocial na prestação de cuidado no bem-estar subjetivo dos cuidadores informais [dissertação]. Beja: Instituto Politécnico de Beja, Escola Superior de Educação; 2017. 207 p.

22. Kluthcovsky ACGC, Kluthcovsky FA. O WHOQOLbref, um instrumento para avaliar qualidade de vida: uma revisão sistemática. Rev Psiquiatr Rio Gd Sul. 2009;31(3 Supl):1-12.

23. Araujo JS, Vidal GM, Brito FN, Gonçalves DCA, Leite DKM, Dutra CDT, et al. Perfil dos cuidadores e as dificuldades enfrentadas no cuidado ao idoso, em Ananindeua, PA. Rev Bras Geriatr Gerontol. 2013;16(1):149-58.
24. Guedes C. Itinerários do cuidar em doenças falciformes e suas repercussões na vida de mulheres. Textos Contextos. 2016;15(2):370-81.

25. Moreira ACA, Silva MJ, Darder JJT, Coutinho JFV, Vasconcelos MIO, Marques MB. Effectiveness of an educational intervention on knowledge-attitudepractice of older adults' caregivers. Rev Bras Enferm. 2018;71(3):1055-62.

26. Faleiros AH, Santos CA, Martins CR, Holanda RA, Souza NLSA, Araújo CLO. Os desafios do cuidar: revisão bibliográfica, sobrecargas e satisfações do cuidador de idosos. Janus. 2015;12(22):59-68.

27. Nobre IDN, Lemos CS, Pardini ACG, Carvalho J, Salles ICD. Ansiedade, depressão e desesperança no cuidador familiar de pacientes com alterações neuropsicológicas. Acta Fisiátrica. 2015;22(4):160-5.

28. Avelar TMT, Storch AS, Castro LA, Azevedo GVMM, Ferraz L, Lopes PF. Oxidative stress in the pathophysiology of metabolic syndrome: which mechanisms are involved? J Bras Patol Med Lab. 2015;51(4):231-9.

29. Lutomski JE, Baars MAE, Schalk BWM, Boter H, Buurman BM, den Elzen WPJ, et al. The development of the older persons and informal caregivers survey minimum DataSet (TOPICS-MDS): a large-scale data sharing initiative. PLoS ONE. 2013;8(12):e81673 [9 p.].

30. Lethin C, Renom-Guiteras A, Zwakhalen S, SotoMartin M, Saks K, Zabalegui A, et al. Psychological well-being over time among informal caregivers caring for persons with dementia living at home. Aging Ment Health. 2017;21(11):1138-46.

31. Korsager LM, Matchkov VV. Hypertension and physical exercise: the role of oxidative stress. Medicina (Kaunas). 2016;52(1):19-27.

32. Oguntibeju OO. Type 2 diabetes mellitus, oxidative stress and inflammation: examining the links. Int J Physiol Pathophysiol Pharmacol. 2019;11(3):45-63. 


\section{ERRATUM}

In the original article "Oxidative stress among informal caregivers", published in the Revista Brasileira de Geriatria e Gerontologia v. 22, n. 4, p. 110-119, 2019, DOI: http://dx.doi.org/10.1590/1981-22562019022.190037, the names of one the authors on p. 110 is incorrect.

Instead of Gilsenir Prevelato de Oliveira Dátilo

the reference should read Gilsenir Maria Prevelato de Almeida Dátilo, in accordance with the following order of authors:

- Natália Ramos Imamura de Vasconcelos

- Gilsenir Maria Prevelato de Almeida Dátilo

- Agnaldo Bruno Chies

- Eduardo Federighi Baisi Chagas

- Thiago José Querino de Vasconcelos

- Pedro Marco Karan Barbosa 